The short answer is to get those seniors moving, as early as possible while in hospital, Brown says. "We need to be jumping on this mobility issue from the moment they come in the door and not waiting until discharge and realizing that they're not capable of walking anymore."

But hospitals typically aren't designed, or inclined, to promote mobility, she notes. "The television is directly over the bed. Often times, there's only one chair in the room, and so if you have company you're going to stay in the bed, and people aren't really encouraged to sit up for meals because we just don't think about it."

There's also a lack of destinations of interest to patients, Brown notes. "We've talked about having some sort of destination in the VA [Veteran Affairs System], for example, a big screen TV playing the football game, some place that is more interesting to walk to."

Brown notes that several newer units for acute care of the elderly are being designed with communal dining areas, to ensure that patients get moving at least three times a day.

Another solution that Brown's facility has adopted is appointing a cohort of "walking aides" whose mission is to persuade patients to move. "If you get walking aides who are entertaining, then it becomes a social event. There are ways to make it interesting. If we walk in silence that's boring, if we walk and talk then it becomes much more acceptable."

Several facilities in Ontario are also exploring means of improving senior mobility as part of a decision in September 2011 to make the promotion of early mobilization as a clinical priority of the Senior Friendly Hospital Strategy of the province's Local Health Integration Networks.

"The goals of the intervention are to ensure that people are assessed early, within 24 hours of admission, and to encourage mobility to the maximum potential of the patient three times a day," says Dr. Barbara Liu, executive director of the Regional Geriatric Program of Toronto and co-leader of MOVE ON (Mobilization of Vulnerable Elders in Ontario).

The MOVE ON initiative has developed a series of educational modules, posters, worksheets, assessment algorithms and patient handouts that have been made available in 14 academic hospitals and are adaptable to "different hospital units and different patient populations," Liu says.

At Sunnybrook Health Sciences Centre, where Liu works as a geriatrician, the facility has developed a volun- teer program to promote mobility among the elderly and redesigned the environment to promote mobility. "We created a checklist for reducing clutter in the hallways" and making it easier for patients to safely navigate hallways by using handrails, Liu says. "On some of our floors we have these chair stations that are situated around the unit. These are places where people can sit down and rest. And these chair stations also have some suggested exercises that you can perform while sitting."

Staff and patients appear to have responded enthusiastically. One patient, a 65-year-old woman named Linda, who asks that her surname not be disclosed, credits the MOVE ON program with preventing her functional decline after being hospitalized as a result of fall. Initially confined to a wheelchair, she found herself moving with the assistance of a walker after two weeks, and her wheelchair consigned to a corner. "I feel a lot more mobile, a lot more secure," she says. "You gotta walk, if you don't walk you're in big trouble. Just generally speaking, it makes sense. We've walked all our lives. It's no good to anybody young or old to not walk." - Nathan Stall MD, Toronto, Ont.

CMAJ 2012. DOI:10.1503/cmaj.109-428

\title{
National standards urged for end-of-life care providers and facilities
}

$\mathrm{P}$ op quiz. If someone wants to start administering palliative, end-of-life or home care in Canada to the terminally ill or elderly, do they need training? Certification? Accreditation? Are they obliged to periodically demonstrate competence or compliance with any manner of standards?

The short answer to all of the above?

For the most part: No.

"Anybody can hang out a shingle and say they're palliative care and nobody can quibble with them," says Dr. Larry Librach, Sun Life Financial
Chair in Bioethics at the University of Toronto in Ontario and past director of the Temmy Latner Centre for Palliative Care at Mount Sinai Hospital.

The absence of national standards and legal requirements essentially means that, in most parts of the country, almost anybody can set themselves up as a provider of the nonpharmaceutical facets of end-of-life care, on an almost fly-by-night basis, even if they lack the resources or training to manage the myriad complexities associated with providing care.

But while Canada isn't exactly overrun with erstwhile providers, sporadic reports of problems and abuses associated with end-of-life and home care indicate that the introduction of standards would elevate the quality of the industry, experts say.

Accreditation of health care providers and facilities is mostly voluntary in Canada. There are few exceptions. It is required in all public and private health care institutions in Quebec, and all facilities supported by regional health authorities in Alberta. Manitoba is also in the process of developing legislation that would compel providers and facilities within regional health authorities to obtain and maintain accreditation. 


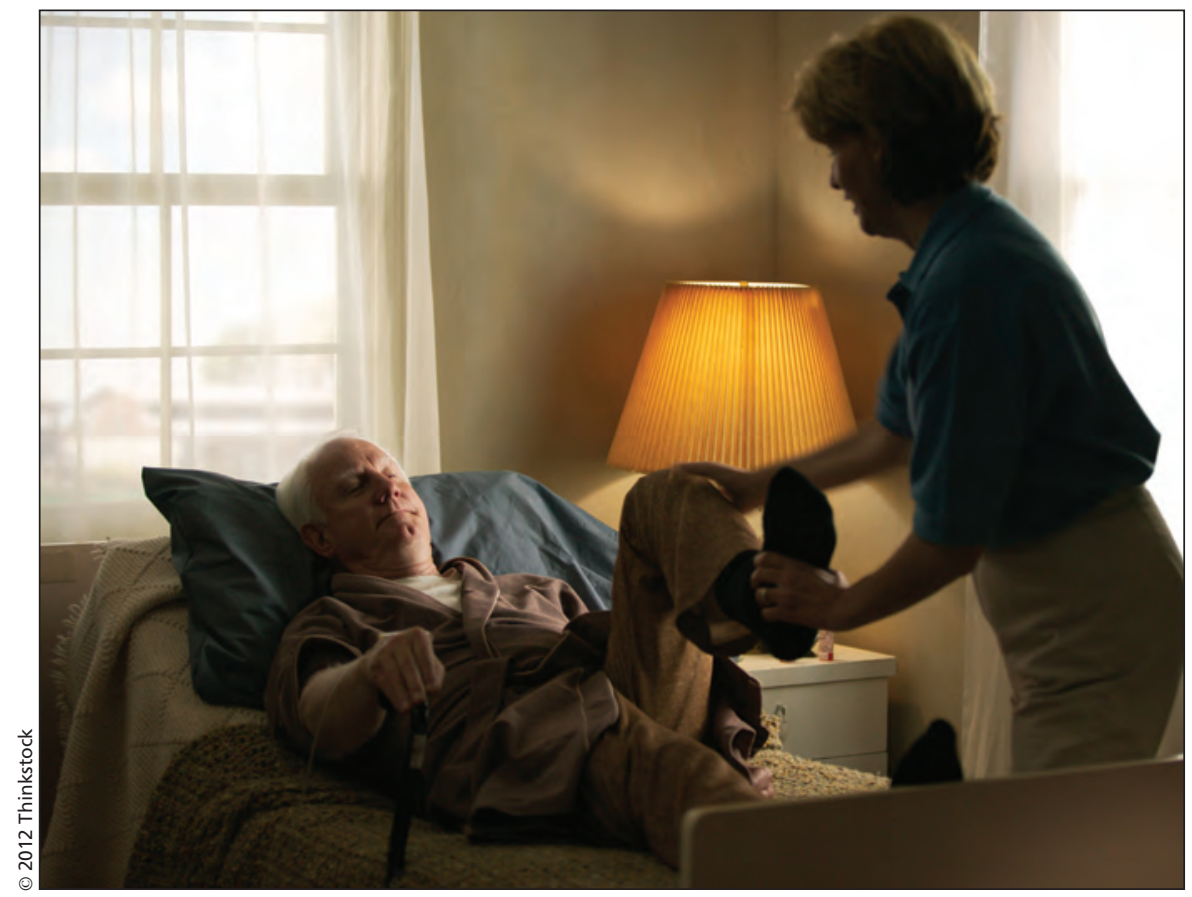

The absence of national standards and legal requirements essentially means that, in most parts of the country, almost anybody can set themselves up as a provider of the nonpharmaceutical facets of end-of-life care, on an almost fly-by-night basis.

Legally requiring providers, facilities or firms offering care to the terminally ill to meet standards could be expected to result in improvements in the quality of that care, says Sharon Baxter, executive director of the Canadian Hospice Palliative Care Association. "Any way you formalize and document and evaluate your program and what you really do is a good thing."

While accreditation of facilities provides "no guarantee that the organization is perfect," it "certainly goes a long way to enabling some consistency of care across the country and also across the health care team," says Wendy Nicklin, president and CEO of Accreditation Canada, a nongovernmental body based in Ottawa, Ontario, that handles the bulk of the accrediting of facilities that is undertaken in Canada.

In the United States, by contrast, national legislation requires that all health facilities and all health care providers must be accredited if they are to receive any manner of public financial support.

"You don't get a cent of money without being accredited, and I think that's the way we should do it," Librach says. "Certainly acute care institutions, I think all home care agencies and all pices or church groups, for example, might provide minimal or substandard care and call it palliative care, Librach explains. Such operations may be run by well-intentioned people but that doesn't mean they have the skills, resources or network required to provide effective care, he adds.

Moreover, Librarch forecasts that such unregulated services will be increasingly uncommon as the provinces move toward regionalized palliative care programs and expanded home care programming.

Such government-led programs impose uniform standards by uniting palliative care units, hospices, home care providers and others under a single umbrella, while typically improving ease of access and easier transition between settings. Ontario has indicated that it is moving toward such regional programming. The approach has also been adopted in Victoria, British Columbia; Edmonton, Alberta; and Calgary, Alberta.

There are also proverbially Canadian jurisdiction obstacles to introducing anything like national standards in the area, Baxter says. "One of the things we've been talking about for many, many years is that each Canadian, no matter where they live, should be able to count on a certain level of care at the end of their lives," Baxter says. "We're not there yet because each of the provinces sort of do their own thing."

There'd also likely be objections from many facilities if nationwide accreditation was imposed on them, Librach says. Some nursing homes and residential care facilities would likely object because "they don't want to air their dirty laundry."

But the consequence is that the general public has a low opinion of such facilities, adds Librach, who estimates that $16 \%$ of people in Ontario die in nursing homes and likely receive substandard care due to sparse funding and nursing support. "Most of us, if we're asked if we want to go into a nursing home, say 'oh my God, no!' It's not because you might be sick and need the care; it's just you don't receive the care." - Michael Monette, CMAJ

CMAJ 2012. DOI:10.1503/cmaj.109-4256 